Mechanical properties enhancement of additive manufactured Ti-6Al-4V by machine hammer peening. In: Advanced Surface Enhancement: Proceedings of the 1st International Conference on Advanced

\title{
Mechanical Properties Enhancement of Additive Manufactured Ti-6Al-4V by Machine Hammer Peening
}

\author{
Leonor Neto $^{1}$, Stewart Williams ${ }^{1}$, Jialuo Ding ${ }^{1}$, Jan Hönnige $^{1}$ and Filomeno Martina ${ }^{1}$ \\ ${ }^{1}$ Cranfield University, Cranfield MK43 0AL, UK
}

\begin{abstract}
Wire + Arc Additive Manufacturing (WAAM) is a technology potentially offering reduction of material wastage, costs and shorter lead-times. It is being considered as a technology that could replace conventional manufacturing processes of Ti$6 \mathrm{Al}-4 \mathrm{~V}$, such as machining from wrought or forged materials. However, WAAM Ti$6 \mathrm{Al}-4 \mathrm{~V}$ is characterized by coarse $\beta$-grains, which can extend through several deposited layers resulting in strong texture and anisotropy. As a solution, inter-pass cold rolling has been proven to promote grain refinement, texture modification and improvement of material strength by plastically deforming the material between each deposited layer. Nevertheless, with the increased interest in the WAAM technology, the complexity and size of the deposited parts has increased, and its application can be hindered by the low speed and complex/costly equipment required to perform rolling at this scale. Therefore, Machine Hammer Peening (MHP) has been studied as an alternative cold work process. MHP can be used robotically, offering greater flexibility and speed, and it can be applied easily to any large-scale geometry. Similarly to rolling, MHP is applied between each deposited layer with the new ECOROLL peening machine and, consequently, it is possible to eliminate texturing and reduce the $\beta$-grains size from centimeters long to approximately 1 to $2 \mathrm{~mm}$. This effect is studied for thin and thick walls and no considerable change in grain size is observed, proving the applicability of MHP to large components. The yield strength and ultimate tensile strength increases to $907 \mathrm{MPa}$ and $993 \mathrm{MPa}$, respectively, while still having excellent ductility. This grain refinement may also improve fatigue life and induce a decrease in crack propagation rate. In this study, it has been shown that MHP is a suitable process for WAAM Ti-6Al-4V applications, can be applied robotically and the grain refinement induced by very small plastic deformations can increase mechanical properties.
\end{abstract}

Keywords: Wire plus Arc Additive Manufacturing, Machine Hammer Peening, Titanium, Grain refinement, Mechanical Properties.

\section{Introduction}

Wire + Arc Additive Manufacturing (WAAM) is a process suitable for production of medium to large components with medium complexity. It promises a reduction of production time, material wastage and overall cost of equipment and manufacturing [1]. For these reasons, industrial sectors have been showing an increasing interest in this technology. Particularly the aerospace industry sees the potential of applying WAAM 
to high strength materials, such as Ti-6Al-4V, which are difficult and costly to manufacture when using conventional manufacturing processes [2]. WAAM technology has been widely reported for the deposition of Ti-6Al-4V alloy [2-4], but its industrial application is limited by the lower and anisotropic mechanical properties in the as-deposited condition, which while being above the Additive AMS 4999 specification are lower than wrought alloys. This is a result of the typical macrostructure of WAAM Ti-6Al$4 \mathrm{~V}$ that is characterized by coarse columnar prior- $\beta$ grains, which can extend several centimeters in the building direction (vertical direction). The preferential growth of prior- $\beta$ grains results in a higher yield and ultimate tensile strength and lower elongation in the horizontal direction when compared with the vertical direction [2]. Also, the microstructure of Ti-6Al-4V WAAM is a crucial factor, affecting the fatigue life of the components. In the last deposited layer of a WAAM built wall, the microstructure is predominantly composed of fine Widmanstätten $\alpha$, while the remaining wall shows coarser Widmanstätten $\alpha$. This coarse lamellar microstructure of as deposited WAAM Ti-6Al-4V has been reported as beneficial for a decrease in the fatigue crack growth [5-6]. It is also shown that the decrease of the lamellae size increases the strength of the material [7].

Martina et. al [7] shows that the application of inter-pass cold rolling induces microstructural changes to Ti-6Al-4V WAAM material. This process consists of applying a defined load on the top surface of each layer through a roller and redepositing a subsequent layer. This procedure is repeated until the desired geometry is obtained. The combination of the applied plastic strain and heating the material above the recrystallization temperature induces grain refinement of the initially columnar prior- $\beta$ grains into very small equiaxed grains. The grain size varies according to the load applied and roller design but ranges from approximately 139 to $6 \mu \mathrm{m}$ for loads of 50 and $75 \mathrm{kN}$, respectively. This is compared to the unrolled grain size of a few to tens of $\mathrm{mm}$. In the same study, it was also observed that there was a decrease of $\alpha$ lamellae thickness with an increase of applied load. Both changes in the microstructure resulted in isotropic properties and increased strength. Qiu [8] also does a preliminary study of the fatigue crack propagation rate of inter-pass rolled samples and concludes that there is an improvement of fatigue crack growth properties when compared with unrolled WAAM and wrought materials. Isotropic properties are also achieved.

With the development of the WAAM technology, there is an increasing demand for more complex and larger components which precludes the use of a rolling process. For inter-pass rolling, a stiff gantry is required in order to apply loads of up to $100 \mathrm{kN}$, which is costly and limits the design freedom of WAAM applications [9,10]. Also, the rolling speed reported ranges from 3 to $7 \mathrm{~mm} / \mathrm{s}$ [7,11], which may increase significantly the production time of the WAAM components. Machine Hammer Peening (MHP) has been previously studied as an alternative to this technology [11-13]. It is shown that MHP has the capability of refining the previously columnar $\beta$ grains and that it can be applied robotically, guaranteeing the flexibility and repeatability required to employ this technology to WAAM components. The MHP speed is also $18 \mathrm{~mm} / \mathrm{s}$ [11], which is much greater than rolling, although the transformed area is not as wide as with rolling. In another study [13], it is also reported that an increase in tensile properties and 
grain refinement is achieved, but the methodology used for MHP and deposition is unclear.

This paper aims to further understand the capability of MHP as an alternative or aid to the already established cold rolling process. The microstructure changes are studied for thin and thick walls and linked with an observed increase of tensile properties and prediction of fatigue behavior.

\section{Experimental Work}

\subsection{Manufacturing and Setup of WAAM Samples}

The as-deposited and inter-pass MHP samples are built using a robotic arm, with an integrated plasma transferred arc torch with wire feeder and an MHP ECOpeen-C tool, as shown in Fig. 1. After each deposited layer, the robotic arm is rotated 90 degrees to obtain a vertical position for the ECOpeen-C tool. This rotation is repeated every layer to perform inter-pass MHP and inverted again for deposition.

To deposit Ti-6Al-4V wire, an EWM T552 Tetrix Plasma power source is used. The wire is supplied by Perryman and its composition is shown in Table 1. For all samples, the substrates of the same alloy are cut to a dimension of 90x350x8 $\mathrm{mm}$. To prevent oxidation of the deposited material, a local shielding device is employed with a gas flow rate of $70 \mathrm{l} / \mathrm{min}$ of pure-shield argon $(99.99 \%$ ) [14]. Two different wall geometries are produced - thin and thick walls. For thin walls $(<10 \mathrm{~mm})$, single bead tracks are deposited for a length of $315 \mathrm{~mm}$ up to a height of $130 \mathrm{~mm}$ which consisted of 110 layers. The thick walls are deposited using an oscillation strategy, which consists of moving the torch in a squared zig zag pattern with the oscillation width determining the width of the wall $(\sim 20 \mathrm{~mm})$ and a step advancement in the direction of the length of the wall of $4 \mathrm{~mm}$. 10 layers are deposited for this condition giving a wall height of approximately $25 \mathrm{~mm}$. A dwelling temperature of $140^{\circ} \mathrm{C}$ is kept for as deposited and inter-pass MHP samples. This control is carried out with a touch probe sensor applied between each layer in the center of the wall. Further deposition parameters are in Table 2.

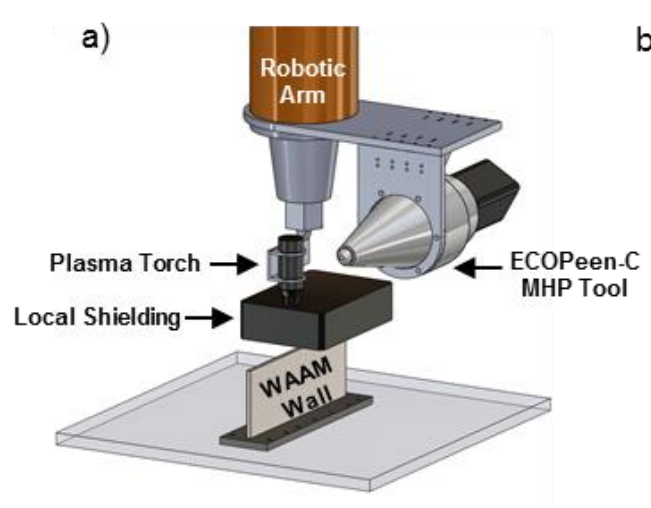

b)

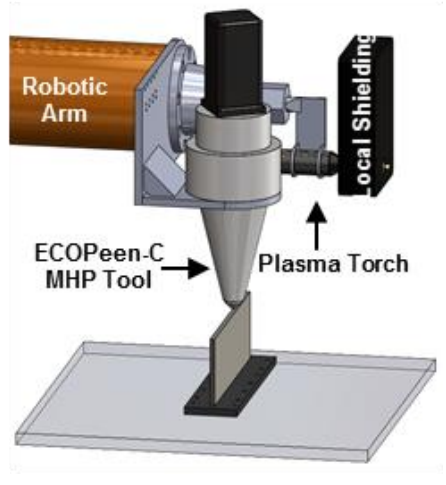

Fig. 1. Experimental set-up (a) ready for deposition and (b) after a $90^{\circ}$ rotation to vertically position the ECOpeen-C tool and apply MHP 
Table 1. Wire composition [WT\%]

\begin{tabular}{llllllll}
\hline $\mathrm{Ti}$ & $\mathrm{Al}$ & $\mathrm{V}$ & $\mathrm{Fe}$ & $\mathrm{O}$ & $\mathrm{C}$ & $\mathrm{N}$ & Others \\
\hline Balance & $6.14-6.15$ & $3.91-3.94$ & $0.17-0.18$ & 0.15 & 0.021 & $0.007-0.008$ & 0.0172 \\
\hline
\end{tabular}

Table 2. Welding parameters for thin and thick (oscillated) walls

\begin{tabular}{lll} 
Deposition Parameter of: & Thin walls & Thick walls \\
\hline Current $[\mathrm{A}]$ & 145 & 170 \\
Wire Feed Speed $[\mathrm{m} / \mathbf{m i n}]$ & 2.4 & 3 \\
Travel Speed $[\mathrm{mm} / \mathrm{s}]$ & 5 & 6.2 \\
Wire diameter $[\mathrm{mm}]$ & 1.2 & 1.2 \\
Work Piece Distance $[\mathrm{mm}]$ & 8 & 8 \\
Dwelling Temperature $\left[{ }^{\circ} \mathrm{C}\right]$ & $140 \pm 10$ & $140 \pm 10$ \\
Plasma Gas Flow $[1 / \mathrm{min}]$ & 0.8 & 0.8 \\
Shielding Gas Flow $[\mathbf{l} / \mathbf{m i n}]$ & 8 & 8
\end{tabular}

The ECOpeen-C is an electro-driven MHP tool developed by ECOROLL AG, which allows a variable impact energy range from 50 to $700 \mathrm{~mJ}$ and has the capability of adapting to uneven surfaces up to $4 \mathrm{~mm}$ (stroke). In this initial study, an energy of 700 $\mathrm{mJ}$ is used and this tool has proven to be able to adapt to the slight uneven WAAM top layers both in thin and thick geometries, providing a consistent MHP pattern. For this energy level, the tool frequency of $225 \mathrm{~Hz}$ is used to obtain an indentation distance of $0.5 \mathrm{~mm}$ (distance between each impact of the tool into the material - Fig. 2), the travel speed of the robotic arm is set at $112.5 \mathrm{~mm} / \mathrm{s}$. The diameter of the tool insert has a radius of $10 \mathrm{~mm}$. For thin walls, a single peening line is employed, as shown in Fig. 2 a) and b) and highlighted in blue. For thick walls, a MHP squared pattern is used for a length of $5 \mathrm{~mm}$ (Fig. $2 \mathrm{c})$ ).

a)

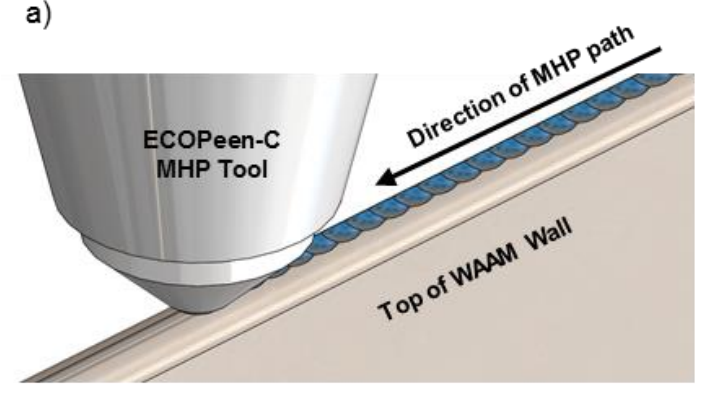

b)

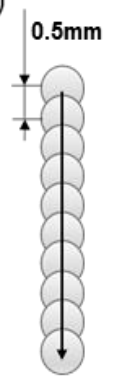

c)

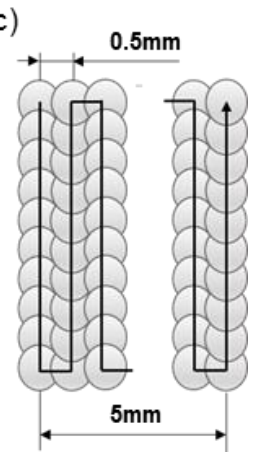

Fig. 2. Thin wall with (a) top layer MHP with a peening line (blue colored) and tool paths for (b) peening line of thin walls and peening square of oscillated thick walls. A $0.5 \mathrm{~mm}$ indentation distance is kept for all directions. 


\subsection{Material Characterization and testing}

For each condition tested, a cross section is cut in the perpendicular direction to the MHP path (vertical cut), hot mounted in conductive resin, grinded and polished. For optical microscopy and Scanning Electrode Microscope (SEM) analysis, etching with a diluted solution of hydrofluoric acid is applied. Eight SEM images are captured using a backscatter detector for higher contrast imaging of $\alpha$ lamellae size. To measure the size of the prior $\beta$-grains, a contour is drawn to outline the shape and size of each grain, which was after measured in both the vertical and horizontal directions. Only grains under the MHP paths are measured in three different locations.

To obtain a microhardness profile, a Zwick/Roell ZHV hardness machine is used with a load of $1 \mathrm{~kg}$ and a dwell time of 15 seconds. For thick walls, 10 parallel lines spaced $0.2 \mathrm{~mm}$ from each other are measured from the top peened layer until the substrate. The spacing between each measurement in the same line was also $0.2 \mathrm{~mm}$. For thin walls, the same spacing is used but only 5 parallel lines are measured, due to the width of impact of the single path of MHP applied.

Tensile testing is carried out for both as deposited and inter-pass MHP conditions of thin walls. The orientation of testing is shown in Fig. 3 a), where five coupons in the vertical (build direction) and horizontal (deposition direction) directions are extracted following the dimensions in Fig. 3 b).

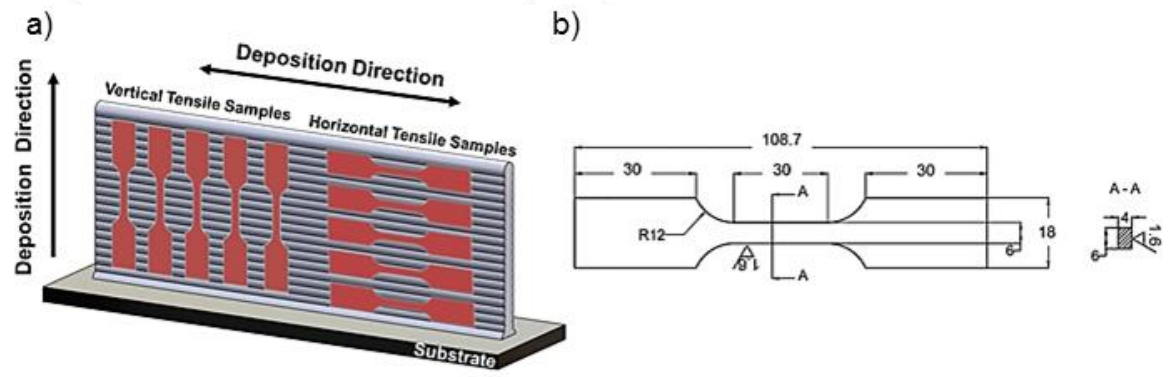

Fig. 3. Tensile specimens (a) position and (b) dimensions of the coupons (all in $\mathrm{mm}$ )

\section{$3 \quad$ Results and Discussion}

\subsection{Effect of MHP on Grain Refinement}

The $\beta$ grain refinement achieved by applying inter-pass MHP is shown in Fig. 4. Fig. 4 a) shows the contrast between the long columnar grains of the as deposited condition and the refined grains after applying inter-pass MHP in thin walls. This effect is explained by Donoghue et al. [15] in which it is suggested that exposing the plastically deformed material to temperatures above $\beta$ transus activates grain refinement. The average $\beta$-grain size is approximately $1 \mathrm{~mm}$ but with a large variation of size, ranging from $200 \mu \mathrm{m}$ to more than $2 \mathrm{~mm}$ long, as is evidenced in Fig. 4 b). Interestingly, similar grain sizes are achieved in a study by Hönnige et al. [11], even though a much lower energy impact tool is used. The grain size is still larger than the one achieved by inter- 
pass cold rolling [7]. However, the ideal beta grain size for industrial applications is still unknown and the grain size achieved by MHP could be enough. Fig. 4 c) shows the grain refinement from as deposited to inter-pass MHP samples of an oscillated thick wall. The MHP pattern is only applied at the center of the deposited material so the grains in the center are refined but there are still columnar beta grains at the edges of the wall. Fig. 4 d) shows a magnified image of the central area for both as deposited and MHP conditions of oscillation strategy. An average grain size of approximately 1.4 $\mathrm{mm}$ is measured for the MHP condition, with a similar variation of size for the thin wall. Although for oscillated deposition the material is exposed to higher temperatures for a longer period, no considerable changes of grain size are observed when comparing with thin walls. Similarly to what is reported in Hönnige et. al [12], grain refinement is observed where there was no strain measured. Nevertheless, in general, the beta grain size is in the order of the layer height. Thus, to obtain grain refinement, the magnitude of MHP or the deposition strategy are not controlling parameters.

a)
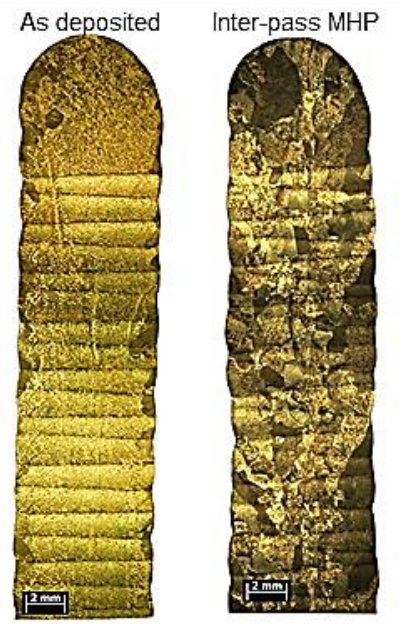

b) Inter-pass MHP

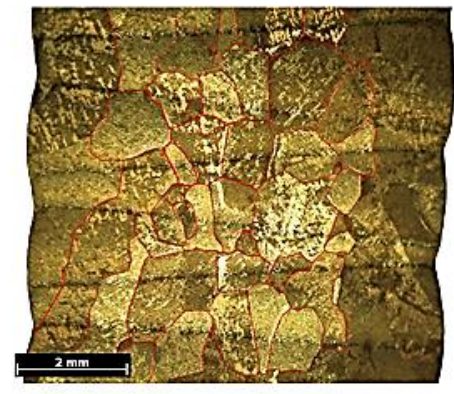

c)

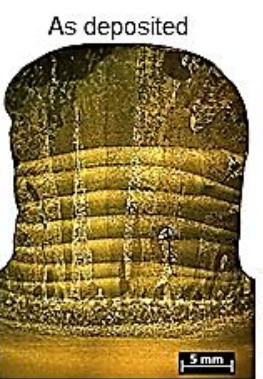

Inter-pass MHP

d) As deposited Inter-pass MHP
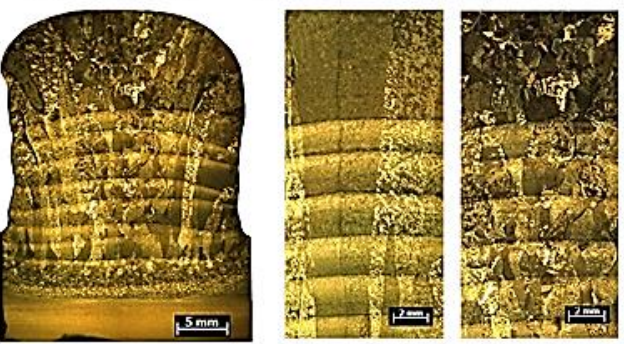

Fig. 4. Macrostructure of (a) thin walls as deposited and after inter-pass MHP, (b) an amplified grain size of the MHP sample, (c) oscillated thick walls as deposited and inter-pass MHP and (d) amplified macrostructure for grain size inspection. 


\subsection{Effect of MHP on Mechanical Properties}

\section{Microhardness}

The measurements of microhardness show a visible increase of hardness for the interpass MHP samples when compared with the as deposited condition. Near the top surface, the hardness magnitude is similar for the thin and thick inter-pass MHP samples, but it is detected a change of depth of work hardening effect by the drop of magnitude in the hardness profiles between the thin and thick walls of inter-pass MHP. For the thick inter-pass MHP sample, an impact of approximately $2 \mathrm{~mm}$ is detected while for thin inter-pass MHP it is approximately $1 \mathrm{~mm}$ (Fig. 5). This is possibly achieved by the combination of two factors. Firstly, by applying a peening pattern to the thick walls instead of only one peening line of the thin walls, the magnitude of cold work increased and, as a result, there is a visible increase of the depth of the MHP impact. Also, due to the increased thickness of the material of the thick walls, the deformation into the material is more laterally constrained and is acting mainly downwards into the material [15]. Further testing of the plastic strain induced should be carried out with different methods to complement the microhardness profile presented.

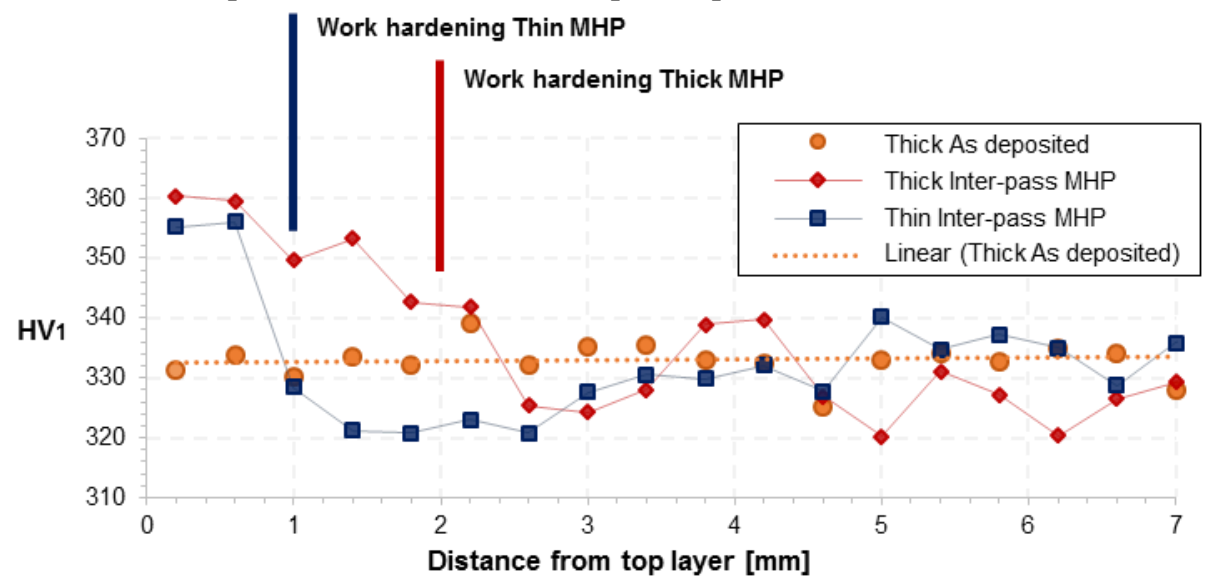

Fig. 5. Micro-hardness profile of MHP and as deposited thick and thin walls

\section{Tensile Properties}

For the as deposited samples, anisotropic properties are obtained. In the horizontal direction, higher strength and lower elongation are observed, when compared to the vertical direction. This is explained by the preferential vertical growth of the prior- $\beta$ grains and agrees with the literature $[2,9,16]$. For both directions of the inter-pass MHP, there is an increase of ultimate tensile and yield strength with a corresponding decrease in elongation of $9 \%$ in the vertical direction, but it is not critical as the elongation is still is above $10 \%$ (Fig. 6). The preferential direction of elongation for the vertical direction with a decrease in strength is eliminated and isotropic properties are achieved through the grain refinement induced by inter-pass MHP. Similar properties have been reported in Byun et al. [13]. 
To compare the properties of MHP in this work with the published inter-pass cold rolling from Martina [16], Fig. 7 is plotted. The properties obtained with MHP are lower when compared to cold rolling loads of $75 \mathrm{kN}$ and similar to $50 \mathrm{kN}$. Slightly lower elongation is obtained compared to rolling but it is still above $10 \%$, which is the reference value of the Wrought AMS 4928 standard.

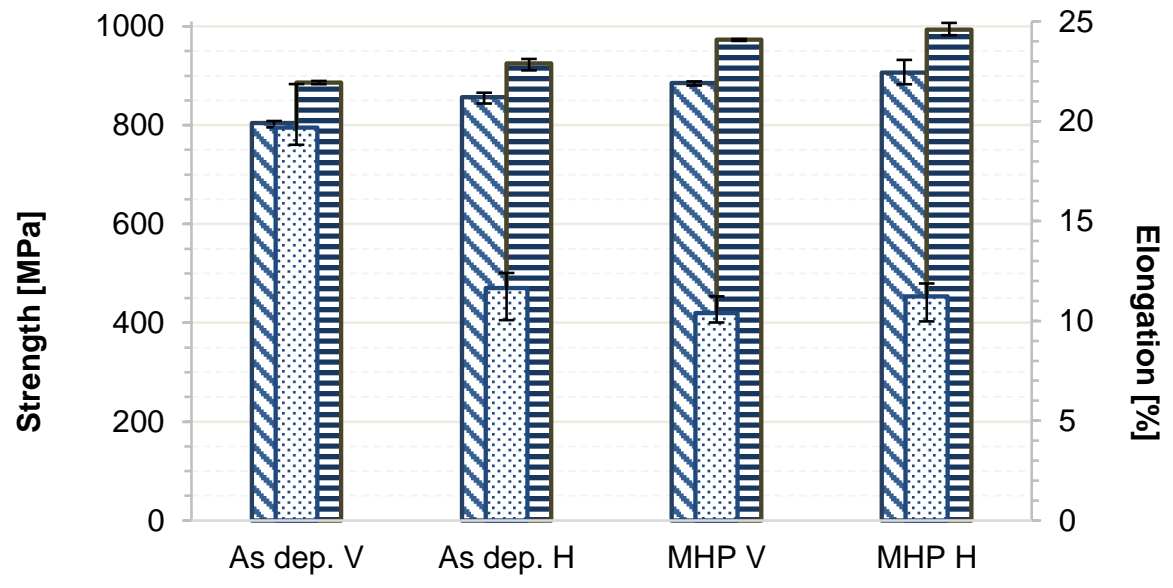

QYield Strength घUltimate Tensile Strength घElongation

Fig. 6. Tensile properties of as deposited and inter-pass MHP of thin walls
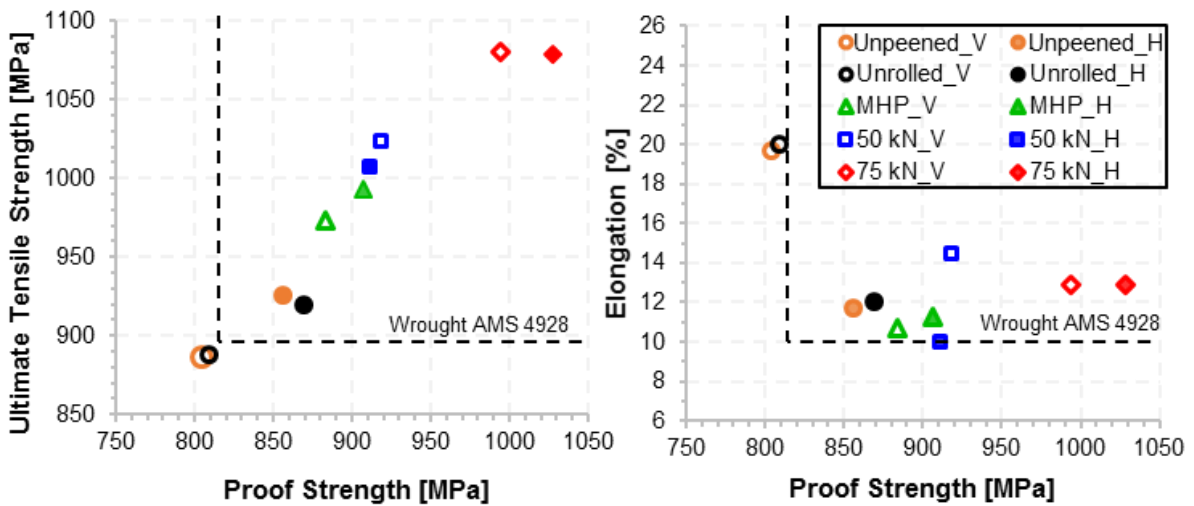

Fig. 7. Comparison of horizontal and vertical tensile properties of inter-pass MHP obtained in the current study and reported inter-pass cold rolling properties [16]. 


\subsection{Strength and Fatigue from $\alpha$ Lamellae Size and prior-beta refinement}

Similar $\alpha$ lamellae thickness is observed for both as deposited and inter-pass MHP thin wall samples, as shown in Fig. 8. This is observed not only in these SEM images but in all acquired images. Martina et. al [4] reported a decrease of $\alpha$ lamellae thickness as the load of cold rolling increased. It is expected that the size of the inter-pass MHP samples showed a lower effect but still a decrease in thickness. It is possible that this divergent result from [4] is due to the different procedure of applying cold work. In [4], rolling is only applied when the component is at room temperature, while the as deposited condition is continuously deposited until the desired geometry is achieved. In the present study a stabilized dwelling temperature at $140^{\circ} \mathrm{C}$ is used for both the MHP and as deposited samples. The different starting temperatures of subsequent deposition, for as deposited and cold rolled specimens, changes the cooling rate for each condition and can promote $\alpha$ lamellae size growth for the lower cooling rate of the as deposited condition [17]. However, in [4] it is possible to observe also a decrease in $\alpha$ lamellae thickness between 50 and $75 \mathrm{kN}$, which suggests that cold work still had an important role in the thickness of the $\alpha$ lamellae. It is possible that the MHP process does not apply deformation with enough magnitude and/or depth to promote a finer $\alpha$ lamellae [5], but further studies are required to achieve a firm conclusion. As the $\alpha$ lamellae microstructure is similar for both as deposited and inter-pass MHP samples, it is likely that the microstructure transformation that leads to the strength increase of MHP samples was the prior- $\beta$ refinement.

It is possible that the fatigue properties of the as deposited and inter-pass MHP samples will be similar, once there is no significant change of $\alpha$ lamellae size. The fatigue properties for as deposited Ti-6Al-4V WAAM walls when compared with wrought material are widely reported in the literature [2,18-21]. The fracture toughness proved to be similar for the WAAM material compared to the wrought material but still has anisotropy [18], while the fatigue crack growth rate of the WAAM material is lower than the wrought material due to the propagation through a tortuous path along its lamellar structure [19-20]. Fatigue life is also improved for WAAM Ti-6Al-4V [2].

Lorant [21] shows the importance of avoiding large columnar beta grains for crack propagation. It was shown that when the crack is aligned with a columnar $\beta$ grain, the path followed the prior- $\beta$ grain boundary. Qiu [8] studied the effect of inter-layer cold rolling on the fatigue crack growth rate and achieved improved and isotropic properties. However, the cause of such improvements is not conclusively correlated with the microstructural changes of the cold rolled material, due to the small sample size tested. 


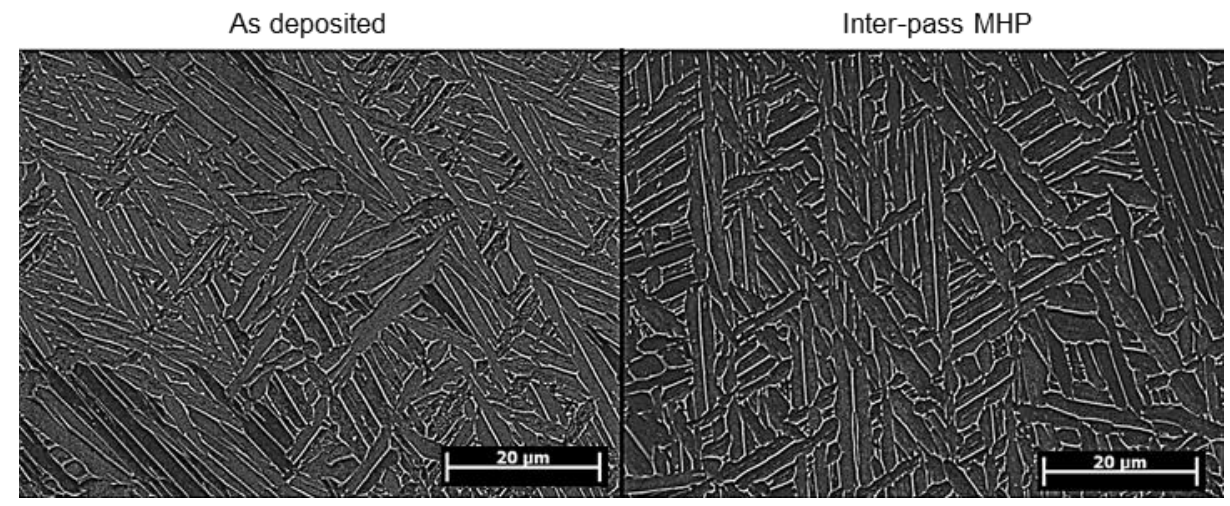

Fig. 8. SEM images of as deposited and inter-pass MHP of thin walls

\section{Conclusions}

The main conclusions redrawn from this study are:

1. Similar grain refinement is achieved by inter-pass MHP of thin walls and oscillated thick walls. This is achieved by the activation of grain refinement of the prior beta grains.

2. An increase of tensile properties and isotropy was achieved by inter-pass MHP. These properties are close to the ones reported for inter-pass cold rolling with $50 \mathrm{kN}$.

3. Similar $\alpha$ lamellae thickness was obtained for as deposited and inter-pass MHP samples.

The present study has proven that MHP can be used as an aid or replacement for cold rolling for WAAM components. Although the properties of as deposited WAAM can be already used for some industrial applications, by applying inter-pass MHP the improvement in flexibility and properties increases the application scope of this novel technology.

\section{Acknowledgments}

The authors would like to thank Alfred Ostertag, Marco Nischkowsky, Karsten Roettger and Stefan Zenk of ECOROLL AG for providing the ECOpeen-C MHP tool and for the operational support, as well as, to Flemming Nielsen, Nisar Shah and Steve Pope for the technical support throughout the experiments carried at the WELPC, Cranfield University. The authors gratefully acknowledge the funding received from the European Union's Horizon 2020 research and innovation program in the project LASIMM (Large Additive Subtractive Integrated Modular Machine) under the grant agreement No 723600. The authors are also grateful for the funding of the Engineering and Physical Sciences Research Council (EPSRC) through New Wire Additive Manufacturing (grant number EP/R027218/1) and Open Architecture Additive Manufacturing (grant number 113164) research program. 


\section{References}

1. Williams, S. W., Martina, F., Addison, A. C., Ding, J., Pardal, G., Colegrove, P.: Wire+ Arc Additive Manufacturing. Materials Science and Technology 32(7), 641647 (2016).

2. Wang, F., Williams, S., Colegrove, P., Antonysamy, A. A.: Microstructure and mechanical properties of wire and arc additive manufactured Ti-6Al-4V. Metallurgical and Materials Transactions A 44(2), 968-977 (2013).

3. Wang, F., Williams, S., Rush, M.: Morphology investigation on direct current pulsed gas tungsten arc welded additive layer manufactured Ti6Al4V alloy. The International Journal of Advanced Manufacturing Technology 57, 597-603 (2010).

4. Martina, F., Mehnen, J., Williams, S. W., Colegrove, P., Wang, F.: Investigation of the benefits of plasma deposition for the additive layer manufacture of Ti-6Al4V. Journal of Materials Processing Technology 212, 1377-1386 (2012).

5. Lütjering, G.: Influence of processing on microstructure and mechanical properties of $(\alpha+\beta)$ titanium alloys. Materials Science and Engineering A 243(1-2), 32-45 (1998).

6. Schroeder, G., Albrecht, J., Luetjering, G.: Fatigue crack propagation in titanium alloys with lamellar and bi-lamellar microstructures. Materials Science and Engineering A 319, 602-606 (2001).

7. Martina, F., Colegrove, P. A., Williams, S. W., Meyer, J.: Microstructure of interpass rolled wire+ arc additive manufacturing Ti-6Al-4V components. Metallurgical and Materials Transactions A 46(12), 6103-6118 (2015).

8. Qiu, X.: Effect of rolling on fatigue crack growth rate of Wire and Arc Additive Manufacture (WAAM) processed Titanium. MSc Thesis, Cranfield University (2013).

9. Colegrove, P. A., Donoghue, J., Martina, F., Gu, J., Prangnell, P., Hönnige, J.: Application of bulk deformation methods for microstructural and material property improvement and residual stress and distortion control in additively manufactured components. Scripta Materialia 135, 111-118 (2017).

10. McAndrew, A. R., Rosales, M. A., Colegrove, P. A., Hönnige, J. R., Ho, A., Fayolle, R., Eyitayo, K., Stan, I., Sukrongpang, P., Crochemore, A., Pinter, Z.: Interpass rolling of Ti-6Al-4V wire+ arc additively manufactured features for microstructural refinement. Additive Manufacturing 21, 340-349 (2018).

11. Hönnige, J. R., Colegrove, P., Williams, S.: Improvement of microstructure and mechanical properties of Wire+ Arc Additively Manufactured Ti-6Al-4V with Machine Hammer Peening. Procedia Engineering 216, 8-17 (2017).

12. Hönnige, J., Colegrove, P., Prangnell, P., Ho, A., Williams, S.: The Effect of Thermal History on Microstructural Evolution, Cold-Work Refinement and \lalpha $\} \wedge \mathrm{b}$ \{eta Growth in Ti-6Al-4V Wire+ Arc AM. Chapter PhD Thesis, Cranfield University (2018).

13. Byun, J. G., Yi, H. J., Cho, S. M.: The Effect of Interpass Peening on Mechanical Properties in Additive Manufacturing of Ti-6Al-4V. Journal of Welding and Joining 35(2), 6-12 (2017).

14. Ding, J., Colegrove, P., Martina, F., Williams, S., Wiktorowicz, R., Palt, M. R.: Development of a laminar flow local shielding device for wire+ arc additive manufacture. Journal of Materials Processing Technology 226: 99-105 (2015). 
15. Donoghue, J., Antonysamy, A. A., Martina, F., Colegrove, P. A., Williams, S. W., Prangnell, P. B.: The effectiveness of combining rolling deformation with WireArc Additive Manufacture on $\beta$-grain refinement and texture modification in $\mathrm{Ti}-$ 6Al-4V. Materials Characterization 114, 103-114 (2016).

16. Martina, F.: Investigation of methods to manipulate geometry, microstructure and mechanical properties in titanium large scale Wire+ Arc Additive Manufacturing. PhD Thesis, Cranfield University (2014).

17. Donachie Jr., M.: Titanium: A Technical Guide 2nd Edition. ASM International, Materials Park (2000).

18. Zhang, X., Martina, F., Ding, J., Wang, X., Williams, S. W.: Fracture toughness and fatigue crack growth rate properties in wire+ arc additive manufactured Ti6Al-4V. Fatigue \& Fracture of Engineering Materials \& Structures 40(5), 790-803 (2017).

19. Zhang, J., Wang, X., Paddea, S., Zhang, X.: Fatigue crack propagation behaviour in wire+ arc additive manufactured Ti-6Al-4V: Effects of microstructure and residual stress. Materials \& Design 90, 551-561 (2016).

20. Nalla, R. K., Ritchie, R. O., Boyce, B. L., Campbell, J. P., Peters, J. O.: Influence of microstructure on high-cycle fatigue of Ti-6Al-4V: bimodal vs. lamellar structures. Metallurgical and Materials Transactions A 33(3), 899-918 (2002).

21. Lorant, E.: Effect of Microstructure on Mechanical Properties of Ti-6S1-4V Structures Made by Additive Layer Manufacturing. MSc Thesis, Cranfield University (2010). 


\section{Mechanical properties enhancement of additive manufactured Ti-6Al-4V by machine hammer peening}

\section{Williams, Stewart W.}

Springer Link

Neto L, Williams S, Ding J, Hönnige J \& Martina F (2020) Mechanical properties enhancement of additive manufactured Ti-6Al-4V by machine hammer peening. In: Itoh, S., Shukla, S. (eds) Advanced Surface Enhancement: Proceedings of the 1st International Conference on Advanced Surface Enhancement (INCASE 2019) - Research Towards Industrialisation, Springer Link, pp. 121-132 https://doi.org/10.1007/978-981-15-0054-1_13

Downloaded from Cranfield Library Services E-Repository 